\title{
Anionic Polymerization of Acrylamide Initiated with the Disodium Salt of Poly(ethylene oxide)
}

\author{
Yoshimasa MUraKami, Toshimitsu SUZUKI, ${ }^{*}$ \\ and Yoshinobu TAKEGAMI* \\ College of General Education, Shinshu University, \\ 3-1-1 Asahi, Matsumoto 390, Japan \\ * Department of Hydrocarbon Chemistry, Faculty of Engineering, \\ Kyoto University, Kyoto 606, Japan
}

(Received October 15, 1984)

\begin{abstract}
Anionic polymerization of acrylamide (AcAm) was initiated with the disodium salt of poly(ethylene oxide) (PEO) in several solvents at various temperatures, and the products were analyzed by ${ }^{1} \mathrm{H}$ and ${ }^{13} \mathrm{C}$ NMR spectroscopies. The Michael type addition of alkoxide anion of PEO to AcAm monomer did not occur in the initiation reaction. Polymerization proceeded exclusively via a hydrogen-transfer mechanism. The polymerization at a relatively low temperature in a polar solvent resulted in the formation of long- and short-chain branchings at the nitrogen atom in amide group and the poly- $\beta$-alanine (PBA) structure. Free rotation of $\mathrm{CO}-\mathrm{N}$ bond at the branching point was observed by high-temperature NMR measurement. In the polymerization at higher temperature in a non-polar solvent, the branching structure was greatly reduced and almost linear PBA was obtained.
\end{abstract}

KEY WORDS Anionic Polymerization / Acrylamide / Poly(ethylene oxide)/ Sodium Alkoxide / Nuclear Magnetic Resonance / Hydrogen-Transfer Polymerization / Chain Branching / Free Rotation / Poly- $\beta$-alanine /

A large number of studies on base-catalyzed polymerization of acrylamide (AcAm) has been reported. ${ }^{1-9}$ Breslow et al. reported that the initiation mechanism involves hydrogen abstraction by a basic initiator from the amide proton in the AcAm monomer so that poly- $\beta$ alanine (PBA) is obtained. ${ }^{1}$ Ogata et al. reported that a basic initiator adds to the AcAm monomer (Michael type addition) and an unstable intermediate is rearranged into a more stable amide anion which further adds to the AcAm monomer. ${ }^{2}$ Nakayama et al. reported from infrared spectra of the polymer of AcAm that the absorptions of primary and secondary amide groups indicate the formation of a copolymer of PBA and vinyl type polymer of AcAm. ${ }^{9}$ Glickson et al. claimed that the primary amide group is not produced by vinyl polymerization but by chain branching. ${ }^{6}$ However, a definite reaction mechanism and structure of the polymer of AcAm have not yet been established.

In previous papers, the anionic polymerizations of various acrylic monomers initiated with the disodium salt of poly(ethylene oxide) (PEO) were reported. ${ }^{10-12}$ It was clarified that PEO fragment in the product is easily detected by NMR spectroscopy. In this work, the anionic polymerization of AcAm was initiated with the disodium salt of PEO. Since whether the initiator fragment (PEO) adds to the AcAm monomer becomes readily apparent, the mechanism of the initiation reaction was investigated. The structure of resulting polymer was also elucidated by NMR analyses. 


\section{EXPERIMENTAL}

\section{Materials}

AcAm and solvents [diglyme, dioxane, tetrahydrofuran (THF), toluene] were purified by the usual methods. Sodium naphthalene was prepared in THF with naphthalene and metallic sodium. $n$-Butyllithium and $t$-butyllithium were prepared in hexane by the usual methods. Commercial PEO \#1000 $\left(M_{n}=980\right)$, PEO $\# 4000\left(M_{n}=3600\right)$ and PEO \#6000 $\left(M_{n}=4600\right)$ were freeze-dried from benzene solutions before use.

\section{Polymerization and Recovery of Polymer}

The polymerization apparatus and procedure were the same as described previously. ${ }^{10-13}$ Since the resulting polymer of AcAm was insoluble in the solvents, it was filtered off and washed with benzene to remove unreacted PEO. Butyllithium was also used as the initiator to obtain PBA.

\section{${ }^{1} H$ and ${ }^{13} C$ NMR Spectra}

${ }^{13} \mathrm{C}$ NMR spectra were recorded in the Pulse Fourier Transformation mode at $25.05 \mathrm{MHz}$ on a JEOL JNM FX 100 and ${ }^{1} \mathrm{H}$ NMR spectra were obtained on a Varian HR 220, using $\mathrm{CF}_{3} \mathrm{COOD}$, DMSO- $d_{6}$, and $\mathrm{D}_{2} \mathrm{O}$ solutions of the polymers at various temperatures.

\section{RESULTS AND DISCUSSION}

\section{Polymerization}

The results are summarized in Table I. The disodium salt of PEO (PEO-Na $\mathrm{Na}_{2}$ initiated the polymerization of AcAm, even at low temperature but the yield of the product was low. Assuming a Michael type addition of PEO$\mathrm{Na}_{2}$ to AcAm monomer to have occurred in the initiation step, the PEO segment should be contained in the resulting polymer. In the polymerizations of methyl methacrylate and methacrylonitrile initiated with $\mathrm{PEO}-\mathrm{Na}_{2}$, a sharp absorption at about $3.7 \mathrm{ppm}$, assignable to the methylene protons of PEO, was observed in the ${ }^{1} \mathrm{H}$ NMR spectra of the resulting polymers. ${ }^{10,12}$ In this polymerization, however, no peak due to PEO was detected in ${ }^{1} \mathrm{H}$ NMR spectra of the resulting polymers. In addition, PEO was almost quantitatively recovered. Consequently, in this polymerization system, the Michael type addition of alkoxide anion of PEO to the AcAm monomer did not occur and polymerization proceeded according to the hydrogen-transfer mechanism proposed by Breslow et al. ${ }^{1}$

\section{${ }^{1} \mathrm{H}$ and ${ }^{13} \mathrm{C} N \mathrm{NM}$ Analyses}

Polymer No. 6 was prepared under conditions that would give the PBA structure. From the ${ }^{1} \mathrm{H}$ NMR spectra of polymer No. 6 , it was concluded that this polymer mainly consists of PBA. ${ }^{6}$ Since the ${ }^{1} \mathrm{H}$ NMR spectra

Table I. Polymerization of AcAm ${ }^{\mathrm{a}}$

\begin{tabular}{|c|c|c|c|c|c|c|}
\hline \multirow{2}{*}{ No. } & \multirow{2}{*}{$\frac{\mathrm{AcAm}}{\mathrm{mmol}}$} & \multicolumn{2}{|c|}{ Initiator } & \multirow{2}{*}{ Solvent } & \multirow{2}{*}{$\frac{\text { Temp }}{{ }^{\circ} \mathrm{C}}$} & \multirow{2}{*}{$\begin{array}{l}\text { Yield } \\
\mathrm{wt} \%\end{array}$} \\
\hline & & Sort & mmol & & & \\
\hline 1 & 29.5 & PEO\#1000- $\mathrm{Na}_{2}$ & 0.2 & THF & 30 & 26 \\
\hline 2 & 10.0 & $\mathrm{PEO} \# 1000-\mathrm{Na}_{2}$ & 0.2 & Diglyme & 80 & 64 \\
\hline 3 & 10.0 & $\mathrm{PEO} \# 4000-\mathrm{Na}_{2}$ & 0.2 & Diglyme & 80 & 90 \\
\hline 4 & 23.9 & $n$-BuLi & 0.3 & Dioxane & 60 & 50 \\
\hline 5 & 11.1 & $\mathrm{PEO} \# 6000-\mathrm{Na}_{2}$ & 0.2 & THF & 30 & 40 \\
\hline 6 & 29.5 & $t$-BuLi & 0.3 & Toluene & 100 & 77 \\
\hline
\end{tabular}

a Reaction time, $20 \mathrm{~h}$. 


\section{in DMSO $-d_{6}$ at $40^{\circ} \mathrm{C}$}
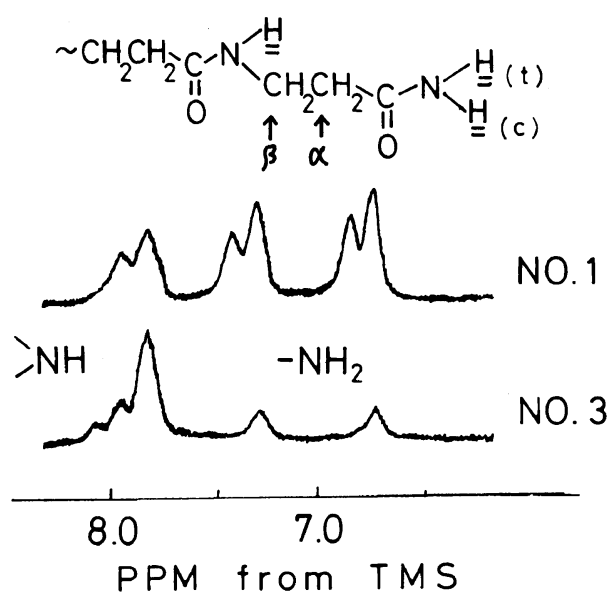

Figure 1. ${ }^{1} \mathrm{H}$ NMR spectra of polymers No. 1 and 3 measured in DMSO $-d_{6}$ at $40^{\circ} \mathrm{C}$.

of polymers No. 2 and 3 were substantially the same as that of polymer No. 6 , they are rich in the PBA structure.

Figure 1 shows the ${ }^{1} \mathrm{H}$ NMR spectra of polymers No. 1 and 3 measured in DMSO- $d_{6}$ at $40^{\circ} \mathrm{C}$ (amide-proton region). Resonances due to amide protons $(6.6-8.1 \mathrm{ppm})$ separated into three peaks and further split into two peaks in the case of polymer No. 1. Similar to the results of Glickson et al., ${ }^{6}$ resonances observed around 6.7 and $7.3 \mathrm{ppm}$ could be assigned to primary amide protons (trans and cis to carbonyl group) and that around $7.9 \mathrm{ppm}$ to a secondary amide proton. The relative intensity of the resonance around $7.9 \mathrm{ppm}$ was less than those around 6.7 and 7.3 ppm for polymer No. 1, compared with polymer No. 3 consisting of PBA. In polymer No. 1, therefore, the content of PBA structure is small, while that of different structures must be considerable. Glickson et al. proposed a chain branching mechanism which would reduce the amount of secondary amide group and produce tertiary amide group. ${ }^{6}$ The presence of branching structures was sub- stantiated by ${ }^{13} \mathrm{C}$ NMR analysis, as described below.

In Figure 2 are shown ${ }^{13} \mathrm{C}$ NMR spectra of polymers No. 1 and 6 measured in $\mathrm{D}_{2} \mathrm{O}$ at $55^{\circ} \mathrm{C}$. In the spectrum of polymer No. 6 consisting of the PBA structure, two sharp peaks were observed at 36.2 and $36.7 \mathrm{ppm}$ (d and e) and two weak absorptions at 43 and $45 \mathrm{ppm}$ (f). On the other hand, in the spectrum of polymer No. 1 containing structures differing from PBA, many peaks were observed between 32 and $37 \mathrm{ppm}$ and the relative intensity of the absorption $f$ was fairly strong. In offresonance measurements, the resonance $f$ and numbers of resonances between 32 and $37 \mathrm{ppm}$ appeared as triplet absorptions. These resonances were thus ascribed to methylene carbons. Although the chemical shift of the resonance $f$ was close to that of the methine carbon resonance, ${ }^{14,15}$ no resonance due to methine carbon was observed in our measurements. This indicates that vinyl polymerization did not occur in this polymerization stystem.

Figure 3 shows the ${ }^{13} \mathrm{C}$ NMR spectra of polymer No. 1, where the $\alpha$ - and $\beta$-protons were selectively irradiated. In this study, the methylene carbons at the $\alpha$ - and $\beta$-positions against carbonyl carbons in the polymer were defined as $\alpha$ - and $\beta$-methylene carbons, respectively. When the $\alpha$-proton was irradiated, two resonances at 43 and 45 ppm (f in Figure 2) appeared as triplet. The pattern of the absorption $\mathrm{f}$ in $\beta$-proton irradiation was the same as that in all proton irradiations. The resonance $\mathrm{f}$ was thus attributed to the $\beta$ methylene carbon. The resonances at 36.2, 36.7, and $36.5 \mathrm{ppm}$ (d, e, and $\mathrm{g}$ in Figure 2) were also found to be due to $\alpha-, \beta$-, and $\beta$ methylene carbons, respectively. The observed coupling constant for the carbon-proton $\left(J_{\mathrm{CH}}\right)$ of the resonances at 36.2 (d) and $36.7 \mathrm{ppm}$ (e) were 129 and $141 \mathrm{~Hz}$, respectively. In the ${ }^{13} \mathrm{C}$ NMR spectrum of $N$-methylacetamide, $J_{\mathrm{CH}}$ of $\mathrm{CH}_{3}-\mathrm{CO}-$ was $129 \mathrm{~Hz}$ and that of $-\mathrm{NH}-\mathrm{CH}_{3}$, $138 \mathrm{~Hz}$. It may thus concluded that the resonances $\mathrm{d}$ and $\mathrm{e}$ are assignable to the $\alpha$ - and $\beta$ - 


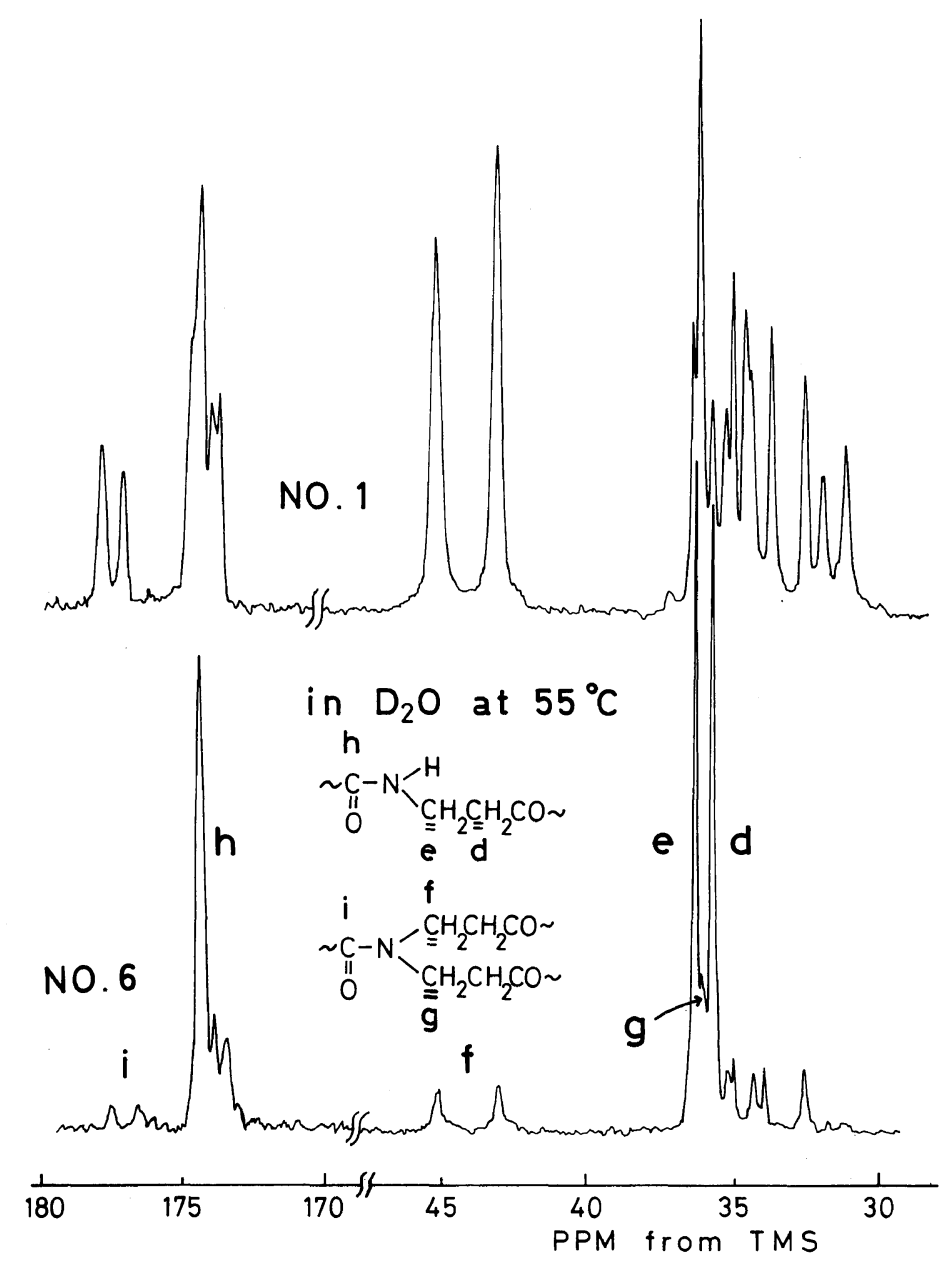

Figure 2. ${ }^{13} \mathrm{C}$ NMR spectra of polymers No. 1 and 6 measured in $\mathrm{D}_{2} \mathrm{O}$ at $55^{\circ} \mathrm{C}$.

methylene carbons (cis to carbonyl group) in the PBA structure. In the ${ }^{13} \mathrm{C}$ NMR spectra of $\mathrm{N}, \mathrm{N}$-dimethylformamide and $\mathrm{N}$-methylformamide, the resonance of the trans methyl carbon to carbonyl group appeared in a magnetic field lower than that of the cis methyl carbon. ${ }^{16}$ Consequently, the resonance $f$ may be assigned to the trans $\beta$-methylene carbon to carbonyl group in tertiary amide group. The tertiary amide group may be possibly produced by chain branching. The hydrogen in the secondary amide group in the polymer was abstracted by metalation and/or chain-transfer reactions and polymerization of
AcAm was initiated, resulting in chain branching (long-chain branching). The relative intensity of the resonances $f$ and $g$ was much stronger in polymer No. 1 than in polymer No. 6 . This indicates the content of the branching structure in polymer No. 1 to be fairly large. It seems likely that resonance due to the cis $\beta$ methylene carbon to carbonyl group in the tertiary amide group appeared at $36.5 \mathrm{ppm}(\mathrm{g})$. As a special case, it is probable that the polymerization of AcAm from the branching point does not proceed further, i.e., only one AcAm monomer attaches to the nitrogen atom in the tertiary amide group (short-chain 


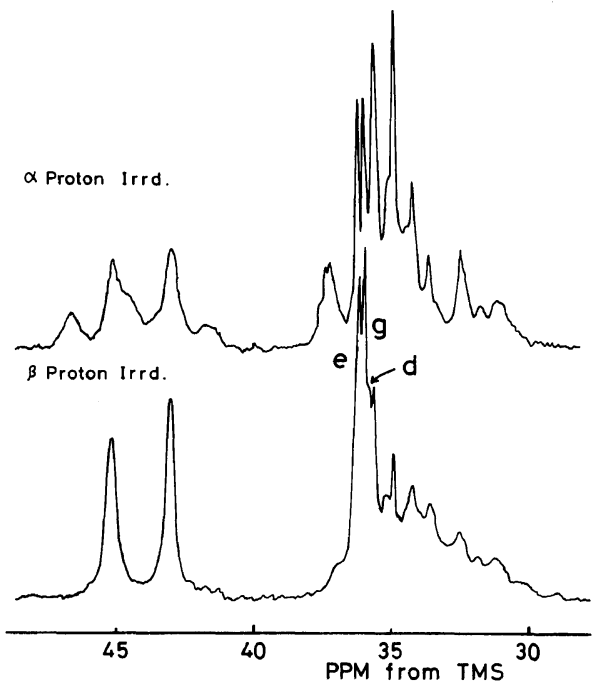

Figure 3. $\alpha$ and $\beta$ protons irradiated selectivedecoupled ${ }^{13} \mathrm{C}$ NMR spectra of polymer No. 1.

branching). In the short-chain branching structure, the trans $\beta$-methylene carbon to carbonyl group is in a different magnetic environment from that of the long-chain branching structure. The resonance ascribed to the trans $\beta$-methylene carbon to carbonyl group (f) thus appeared as two absorptions. It should be noted that various kinds of chain branching are possible. Absorptions in the ${ }^{13} \mathrm{C}$ NMR spectra arising from such structures would appear around $32-36 \mathrm{ppm}$ in a complicated manner, as seen in Figure 2. Resonances due to $\alpha$-methylene carbons in the tertiary amide group may be assumed to appear at $32-36$ ppm.

Figure 2 shows a broad absorption around $174 \mathrm{ppm}(\mathrm{h})$, considered to be an overlapping absorption of peaks due to the carbonyl carbons in the PBA structure and terminal monomer unit. Furthermore, two absorptions are observed around $177 \mathrm{ppm}$ (i). The relative intensity of resonance $i$ was much stronger in polymer No. 1 than in polymer No. 6 as well as in the case of the resonances $f$ and $g$. The resonance $i$ may thus be assigned to the carbonyl carbons of the tertiary amide groups in the short- and long-chain branching polymers.

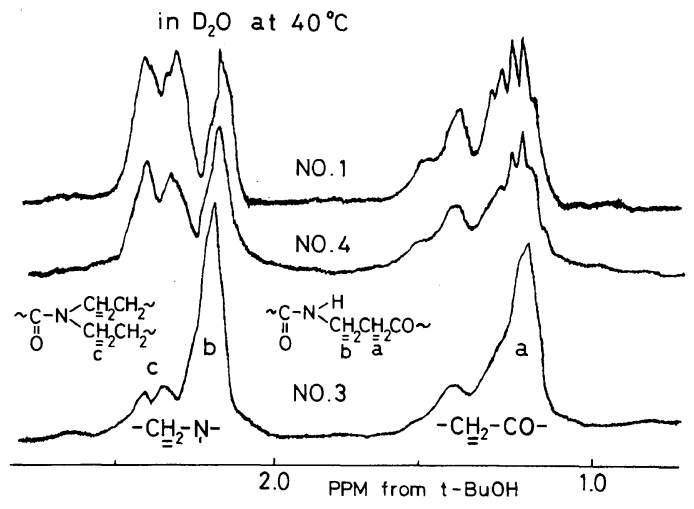

Figure 4. ${ }^{1} \mathrm{H}$ NMR spectra of polymers No. 1, 3, and 4 measured in $\mathrm{D}_{2} \mathrm{O}$ at $40^{\circ} \mathrm{C}$.

The splitting of absorptions due to primary amide protons (cis and trans to carbonyl group) in the ${ }^{1} \mathrm{H}$ NMR spectrum of polymer No. 1 shown in Figure 1 may be ascribable to short- and long-chain branchings.

Figure 4 shows the ${ }^{1} \mathrm{H}$ NMR spectra of aliphatic protons in polymers No. 1,3 , and 4 measured in $\mathrm{D}_{2} \mathrm{O}$ at $40^{\circ} \mathrm{C}$. Since the spectra of polymers No. 1 and 4 were almost identical, the structures of the two polymers are thus almost the same. Since the relative intensity of the absorptions $1-1.6 \mathrm{ppm}$ and $2-2.6 \mathrm{ppm}$ was the same, the former is due to the $\alpha$ methylene protons and the latter to the $\beta$ methylene protons. In the spectra of polymers No. 1 and 4, the relative intensity of the resonances around $2.4 \mathrm{ppm}$ (c) was stronger than in the spectrum of polymer No. 3 mainly consisting of PBA. The resonance $\mathrm{c}$ is, therefore, ascribable to the $\beta$-methylene protons in the tertiary amide group (cis and trans to carbonyl group) produced by chain branching. Resonances due to the $\alpha$-methylene protons in the tertiary amide group presumably appear around $1.45 \mathrm{ppm}$. In the spectrum of polymer No. 3, the relative intensity of the resonances at $1.2 \mathrm{ppm}$ (a) and $2.2 \mathrm{ppm}$ (b) was the same. Consequently, resonances $\mathrm{a}$ and $\mathrm{b}$ can be assigned to the $\alpha$-methylene and $\beta$-methylene protons in the PBA structure, respectively.

Based on the above findings and polymeri- 
zation conditions (polymerization temperature and nature of the solvent), polymers No. 2, 3, and 6 are concluded to consist mainly of PBA and No. 1, 4, and 5 to include a considerable amount of the branching structure.

Figure 5 shows the ${ }^{13} \mathrm{C}$ NMR spectra of polymer No. 1 measured in $\mathrm{D}_{2} \mathrm{O}$ at $55^{\circ} \mathrm{C}$ and $95^{\circ} \mathrm{C}$. In the spectrum at $95^{\circ} \mathrm{C}$, several peaks broadened more than that at $55^{\circ} \mathrm{C}$. Thus, at $95^{\circ} \mathrm{C}$, an exchange of two species clearly occurs at the time scale of NMR, that is, rotation of $\mathrm{CO}-\mathrm{N}$ bond in the tertiary amide group

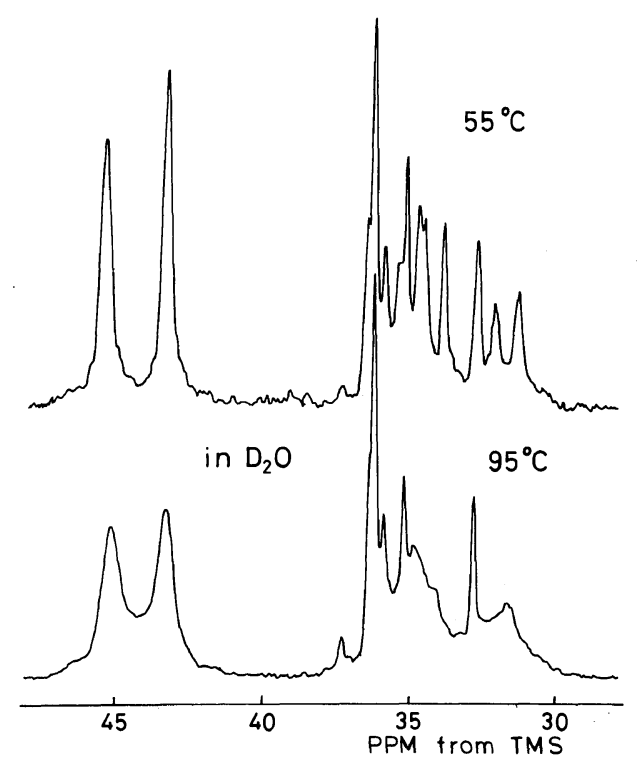

Figure 5. ${ }^{13} \mathrm{C}$ NMR spectra of polymer No. 1 measured in $\mathrm{D}_{2} \mathrm{O}$ at 55 and $95^{\circ} \mathrm{C}$. occurs freely.

As described above, we assigned the absorptions in the NMR spectra of the product. However, a few questions still remain, such as why the relative intensity of the two absorptions around $44 \mathrm{ppm}$ (f) is always the same and why it is fairly strong compared with that of other absorptions. To answer these questions it is considered that, in the ${ }^{13} \mathrm{C}$ NMR spectra, the two absorptions observed at 43 and $45 \mathrm{ppm}$ are due to cis and trans $\beta$ methylene carbons to the carbonyl group in the tertiary amide group, respectively. ${ }^{17}$ However, splitting of the absorption i cannot be explained on this basis. Although our assignments may not be entirely right, they adequately explain the NMR spectra of the product in the present stage.

\section{CONCLUSIONS}

In the initiation reaction, the Michael type addition of alkoxide anion of PEO to the AcAm monomer does not occur. In this polymerization system, vinyl polymerization does not occur and polymerization proceeds according to the hydrogen-transfer mechanism proposed by Breslow et al. ${ }^{1}$

This polymerization system resulted in a polymer of AcAm having various complicated chain branching patterns. Typical examples of the structure of this product are summarized in Scheme I. Glickson et al. proposed that only

(1)<smiles>CCCCC(=O)NCCCC(=O)NCCC</smiles>

(2)<smiles>CCCC(=O)N(C)CCCC(=O)N[C@H](O)[C@H](O)CO</smiles>

(3)

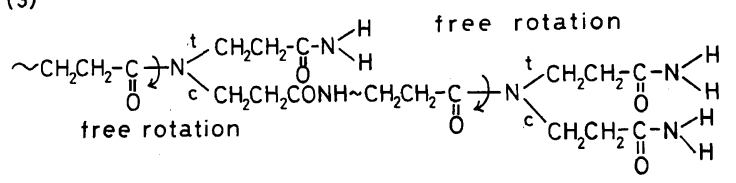

Scheme 1. 
long-chain branching occurs (eq 2) and free rotation of $\mathrm{CO}-\mathrm{N}$ bond takes place only at the chain end. ${ }^{6}$ In addition to the long-chain branching, we consider that short-chain branching also occurs and that free rotation of the $\mathrm{CO}-\mathrm{N}$ bond at $95^{\circ} \mathrm{C}$ takes place even at the branching point. A typical example of shortchain branching is shown in eq 3. In the polymerization at relatively high temperature in a non-polar solvent, the degree of chain branching is greatly reduced and almost linear PBA (eq 1) is obtained as the main product. The polymerization at relatively low temperature in a polar solvent leads to the formation of long- and short-chain branchings as well as the PBA structure.

\section{REFERENCES AND NOTES}

1. D. S. Breslow, G. E. Hulse, and A. S. Matlack, J. Am. Chem. Soc., 79, 3760 (1957).

2. N. Ogata, Makromol. Chem., 40, 55 (1960).

3. F. A. Bovey and G. V. D. Tiers, J. Polym. Sci., A, 1, 849 (1963).
4. H. Tani, N. Oguni, and T. Araki, Makromol Chem., 76, 82 (1964).

5. L. W. Bush and D. S. Breslow, Macromolecules, 1, 189 (1968).

6. J. D. Glickson and J. Applequist, Macromolecules, 2, 628 (1969).

7. J. P. Kennedy and T. Otsu, J. Macromol. Sci. Rev., Macromol. Chem., C6, 237 (1972).

8. S. Dabi and A. Zilkha, Eur. Polym. J., 13, 545 (1977).

9. H. Nakayama, T. Higashimura, and S. Okamura, Kobunshi Kagaku, 23, 433 (1966).

10. T. Suzuki, Y. Murakami, Y. Tsuji, and Y. Takegami, J. Polym. Sci., Polym. Lett. Ed., 14, 675 (1976).

11. T. Suzuki, Y. Murakami, and Y. Takegami, Polym. J., 12, 183 (1980).

12. T. Suzuki, Y. Murakami, and Y. Takegami, Polym. J., 14, 431 (1982).

13. T. Suzuki, Y. Murakami, O. Yamada, and Y. Takegami, J. Macromol. Sci., Chem., A18, 817 (1982).

14. Y. Inoue, T. Fukutomi, and R. Chûjô, Polym. J., 15, 103 (1983).

15. J. E. Lancaster and M. N. O'Connor, J. Polym. Sci., Polym. Lett. Ed., 20, 547 (1982).

16. G. C. Levy and G. L. Nelson, J. Am. Chem. Soc., 94, 4897 (1972).

17. This idea was suggested by the reviewers. The authors gratefully acknowledge them. 